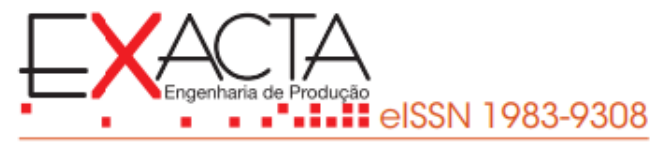

\title{
AVALIAÇÃO DO RESULTADO DE PRODUTOS DE PEQUENA INDÚSTRIA CONSIDERANDO AS DESPESAS FINANCEIRAS ORIUNDAS DA DURAÇÃO DO CICLO FINANCEIRO E DA RESPECTIVA NECESSIDADE DE CAPITAL DE GIRO
}

\section{EVALUATION OF THE RESULT OF SMALL INDUSTRY PRODUCTS CONSIDERING THE FINANCIAL EXPENSES ARISING FROM THE DURATION OF THE FINANCIAL CYCLE AND THE RESPECTIVE WORKING CAPITAL NEED}

Recebido em: 23 nov. 2020

Aprovado em: 13 fev. 2021

Versão do autor aceita publicada online: 13 fev. 2021

Publicado online: 25 jun. 2021

Como citar esse artigo - American Psychological Association (APA):

Wernke, R. (2022, out./dez.). Avaliação do resultado de produtos de pequena indústria considerando as despesas financeiras oriundas da duração do ciclo financeiro e da respectiva necessidade de capital de giro. Exacta. 20(4), 1062-1083. https://doi.org/10.5585/exactaep.2022.18754.

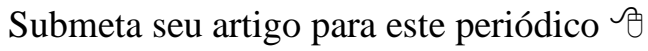

Dados Crossmark 


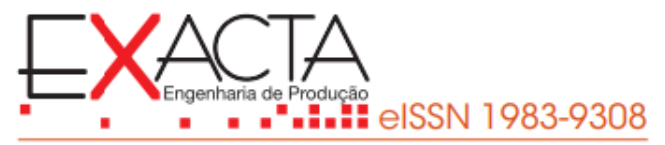

\title{
AVALIAÇÃO DO RESULTADO DE PRODUTOS DE PEQUENA INDÚSTRIA CONSIDERANDO AS DESPESAS FINANCEIRAS ORIUNDAS DA DURAÇÃO DO CICLO FINANCEIRO E DA RESPECTIVA NECESSIDADE DE CAPITAL DE GIRO
}

\author{
EVALUATION OF THE RESULT OF SMALL INDUSTRY PRODUCTS CONSIDERING \\ THE FINANCIAL EXPENSES ARISING FROM THE DURATION OF THE FINANCIAL \\ CYCLE AND THE RESPECTIVE WORKING CAPITAL NEED
}

Rodney Wernke ${ }^{1}$

\author{
${ }^{1}$ Doutor em Engenharia de Produção/UFSC \\ Sem Vínculo Institucional \\ São Ludgero, SC - Brasil \\ rodneywernke1@hotmail.com
}

Recebido em: 23 nov. 2020

Aprovado em: 13 fev. 2021
Resumo: O objetivo da pesquisa foi propor uma equação que permita medir o resultado do produto considerando a duração do ciclo financeiro e a respectiva necessidade de capital de giro no contexto de uma pequena indústria de artefatos de cimento. Foi utilizada metodologia com abordagem qualitativa, tipologia exploratória e o procedimento de estudo de caso. O principal aspecto do estudo é a proposição de metodologia que possibilita considerar, na avaliação do resultado oriundo de cada produto, as despesas financeiras decorrentes do capital de giro necessário para suportar o ciclo financeiro de cada item faturado no período. Portanto, esta pesquisa contribui teoricamente com a proposta de computar as despesas financeiras associadas ao capital de giro necessário para financiar o ciclo financeiro dos produtos na avaliação do resultado destes segmentos. Do ponto de vista prático, contribui com uma ferramenta para ser utilizada pelos gestores de pequenas empresas na avaliação do mix de produtos e na gestão do capital de giro.

Palavras-chave: Ciclo financeiro. Capital de giro. Avaliação do resultado de produtos.

Abstract: The objective of the research was to propose an equation that allows measuring the result of the product considering the duration of the financial cycle and the respective working capital need in the context of a small cement artifact industry. Methodology with a qualitative approach, exploratory typology and the case study procedure was used. The main result of the study is the proposition of a methodology that makes it possible to consider, in the evaluation of the result from each product, the financial expenses arising from the working capital necessary to support the financial cycle of each item billed in the period. Therefore, this research theoretically contributes to the proposal to compute the financial expenses associated with the working capital necessary to finance the financial cycle of the products in the evaluation of the result of these segments. From a practical point of view, it contributes with a tool to be used by managers of small companies in the evaluation of the product mix and in the management of working capital.

Keywords: Financial cycle. Working capital. Evaluation of product results. 


\section{Introdução}

A gestão do capital de giro tem influência em diversos aspectos que impactam no desempenho financeiro (Altaf \& Shah, 2018a; Tsuruta, 2018;) e na rentabilidade das empresas (Amponsah-Kwatiah \& Asiamah, 2020; Sawarni, Narayanasamy, \& Ayyalusamy, 2020), inclusive naquelas de pequeno porte (Wernke \& Junges, 2020; Gorondutse, Ali, Abubakar, \& Naalah, 2017; Mohamad, Rahman, \& Saad, 2017).

Contudo, estudos acerca de como a duração do ciclo financeiro e o dimensionamento da necessidade de capital de giro interferem no resultado dos produtos são, ainda, uma lacuna de pesquisa pouco explorada. Um fator que provavelmente restringe o estudo sobre este aspecto é a indisponibilidade dos dados necessários acerca dos fatores que influenciam o resultado dos produtos nas demonstrações contábeis publicadas, pois estas informações tendem a ser disponíveis apenas internamente.

Nesse rumo, a margem de contribuição tem sido o instrumento utilizado para avaliar o desempenho da rentabilidade dos segmentos de mercado (Guerreiro, 2011; Souza \& Rocha, 2010; Wernke \& Lembeck, 2004). Para essa finalidade, tal forma de mensuração do resultado requer deduzir os custos e as despesas variáveis do produto do respectivo preço de venda (Rojas, 2019; Veljkovic, Koprivica, Radivojevic, \& Mileusnic, 2018; Martins, 2018).

Porém, a margem de contribuição pode ser insuficiente para aferir o efetivo desempenho do produto porque não abrange alguns itens relevantes que estão atrelados à disponibilidade da mercadoria para comercialização. Como exemplos, Wernke (2019) menciona as despesas financeiras decorrentes do ciclo financeiro e da taxa de juros suportada para captar o montante de recursos aplicados no capital de giro necessário para que a empresa possa pagar seus fornecedores antes de receber as vendas efetuadas, mediante a concessão de prazo para seus clientes.

O cômputo desses valores na aferição do resultado proporcionado pelos produtos se coaduna com o posicionamento de Assaf Neto (2014) ao recomendar que as políticas de prazos de estoque, de recebimentos e de pagamentos (que se refletem no ciclo financeiro e, por consequência, no maior ou menor valor da necessidade de capital de giro) devem ser gerenciadas com atenção. O referido autor também aduz que a inadequação do ciclo de conversão de caixa prejudica a lucratividade operacional da empresa, principalmente porque leva à captação de recursos para financiar o capital de giro das operações comerciais cotidianas.

A partir do contexto mencionado emergiu a seguinte questão de pesquisa: como medir o resultado do produto considerando a extensão do ciclo financeiro e a respectiva necessidade de capital de giro no âmbito de uma pequena empresa industrial? Para responder tal pergunta foi estabelecido o objetivo de propor uma equação que permita medir o resultado do produto considerando a duração do 
ciclo financeiro e a decorrente necessidade de capital de giro no contexto de uma pequena indústria de artefatos de cimento.

Uma pesquisa com tal foco pode ser justificada por dois motivos. O primeiro é pela possibilidade de facilitar a otimização da lucratividade de pequenos empreendimentos fabris ou auxiliar na gestão financeira de pequenas empresas industriais, cujas limitações foram apontadas por alguns estudos como um dos fatores que prejudicam o crescimento deste porte empresarial (Baker, Kumar, Colombage, \& Singh, 2017; Pais \& Gama, 2015; Singh \& Kumar, 2014; Carvalho \& Schiozer, 2012).

A segunda razão reside no fato de que, em termos acadêmicos, a gestão financeira de curto prazo ainda é pouco explorada nas pesquisas empíricas (Silva, Camargos, Fonseca, \& Iquiapaza, 2019), pois a literatura de finanças corporativas prioriza a gestão financeira de longo prazo (Chang, 2018; Singh \& Kumar, 2014; Palombini \& Nakamura, 2012; Nazir \& Afza, 2009).

\section{Revisão da literatura}

O capital de giro pode ser conceituado como o montante de recursos necessário para financiar o ciclo financeiro da empresa, que abrange o período entre a data de pagamento dos fornecedores de insumos e o recebimento da venda feita para clientes (Silva et al., 2019; Wernke, 2019).

Pela relevância no cotidiano financeiro empresarial, o gerenciamento do capital de giro foi objeto de estudos que o associam: (i) ao desempenho financeiro das empresas; (ii) à competitividade de mercado advinda da disponibilidade de capital para financiar a concessão de prazos para clientes e (iii) à capacidade de geração de valor para investidores (Altaf \& Shah, 2018a; Kabuye, Kato, Akugizibwe, \& Bugambiro, 2018; Altaf \& Shah, 2018b; Jana, 2018; Altaf, 2018; Nyeadi, Sare \& Aawaar, 2018; Tsuruta, 2018; Baker et al., 2017; Gorondutse et al., 2017; Respatia, 2017; Bruni, 2013; Carvalho \& Schiozer, 2012).

Além disso, do ponto de vista da associação entre o gerenciamento do capital de giro e a lucratividade das empresas (o que se aproxima do foco deste estudo), podem ser mencionadas as publicações de Wernke e Junges (2020), Wernke (2020), Dalci e Ozyapici (2018), Prasad, Narayanasamy, Paul, Chattopadhyay e Saravanan (2018), Oseifuah (2018), Mielcarz, Osiichuk e Wnuczak (2018), Gorondutse et al. (2017), Baker et al. (2017), Mohamad, Rahman e Saad (2017), Ahmed, Mahtab, Islam e Abdullah (2017), Kalaivani e Jothi (2017), Kasozi (2017), Quang (2017) e Thakur e Mukit (2017).

Nessa direção, Gill (2011) argumenta que para dimensionar corretamente o nível do investimento em capital de giro é pertinente avaliar periodicamente os fatores que influenciam na necessidade de captação deste tipo de recurso financeiro, sob pena de prejudicar a liquidez e a rentabilidade do empreendimento. A mesma opinião é corroborada por Assaf Neto (2014) quando 
assevera que a gestão do capital de giro abrange as atividades operacionais e financeiras da companhia que são impactadas pelas políticas de prazos de recebimento, estocagem e pagamento utilizadas.

Esse contexto recomenda, conforme Aminu e Zainudin (2016), que os administradores atentem para a duração do ciclo financeiro, visto que este período expressa o prazo transcorrido entre as datas da compra de insumos e do recebimento das vendas. Ou seja, o monitoramento contínuo é relevante porque uma longa duração do ciclo financeiro dificulta a renovação dos recursos de caixa e pode prejudicar a capacidade de pagamento de dívidas (Kabuye et al., 2018; Steffen, Zanini, Kronbauer, \& Ott, 2014).

Do ponto de vista de sua mensuração, o ciclo financeiro envolve a soma do prazo médio concedido aos clientes com o prazo médio de estocagem dos insumos e a dedução do prazo médio de pagamento de fornecedores (Wernke, 2020; Kabuye et al., 2018; Oseifuah, 2018; Assaf Neto, 2014). A partir disso, a avaliação dos gestores deve considerar a duração do ciclo de conversão de caixa, porque quanto maior for sua extensão, maior será o montante de capital de giro a ser disponibilizado para manter as operações comerciais sem interrupções por insolvência (Wernke \& Junges, 2020; Aminu \& Zainudin, 2016).

A respeito disso é interessante ressaltar que o gerenciamento do capital de giro é uma tarefa difícil porque envolve a determinação do patamar de uso dos passivos circulantes para financiar os ativos circulantes, sendo que o valor do passivo circulante está vinculado a fatores como compras a prazo, despesas e empréstimos de curto prazo (Gitman, 1997). Nessa direção, pode ser utilizado o cálculo da "Necessidade de Capital de Giro (NCG)", proposto por Fleuriet, Kehdy e Blanc (2003), que se diferencia do conceito contábil de "Capital de Giro Líquido (CGL)". Ou seja, as contas de ativo e passivo são reclassificadas em "permanentes" ou "operacionais", conforme as características do ciclo operacional da empresa. Assim, aquelas contas que tiverem movimentação de curto prazo lenta são caracterizadas como "permanentes" ou "não cíclicas", enquanto são classificadas como "operacionais" ou "cíclicas" as contas que têm movimentação contínua e recorrente de valores ao longo do exercício social (Machado, Machado, \& Callado, 2006).

A citada metodologia de dimensionamento da necessidade de capital de giro utiliza os valores obtidos do balanço patrimonial da empresa e, a priori, não permite segregar o volume de recursos demandados individualmente pelos segmentos de mercado (produtos, linhas de mercadorias etc.). Mas, como o objetivo desta pesquisa requer a estimativa do capital de giro que cada produto requer para ser comercializado, foi adotado o cálculo a respeito apresentado por Santana, Backes e Demarchi (2009), que apura o valor do capital de giro multiplicando o ciclo financeiro (em dias) do produto pelo valor monetário $(R \$)$ das respectivas vendas médias diárias. 


\subsection{Margem de contribuição para avaliar o resultado de segmentos de mercado}

A margem de contribuição costuma ser utilizada para medir o resultado de segmentos de mercado, o que pode abranger produtos, grupos, linhas de comercialização, tipos de clientes, territórios de venda, equipes de vendas, unidades de negócio e empresas (Viswanathan, Tillmanns, Krafft, \& Asselmann, 2018; Veljkovic, Koprivica, Radivojevic, \& Mileusnic, 2018; Zin, Bombana, \& Barcellos, 2018; Santos, Cruz, Santos, \& Leone, 2018; Guerreiro, 2011; Wernke \& Lembeck, 2004).

O referido conceito contábil pode ser caracterizado como o valor resultante da dedução dos custos e despesas variáveis das vendas de cada produto (Martins, \& Rocha, 2010). Nesse sentido, Santos et al. (2018) registram que é um parâmetro utilizado para avaliar o desempenho dos produtos comercializados, podendo ser mensurado em valor monetário (R\$) e em percentual (\%).

Em relação às publicações anteriores que visaram aprimorar o conceito (ou as aplicações) de margem de contribuição, foram identificados os seguintes estudos:

a) Rojas (2019) fez a comparação de diversos modelos estatísticos para otimizar as margens de contribuição em fábrica de alimentos.

b) Viswanathan, Tillmanns, Krafft e Asselmann (2018) estudaram como utilizar as indicações dadas por clientes para melhorar a taxa de conversão das referências positivas recebidas em clientes efetivos e otimizar a margem de contribuição de uma empresa de serviços financeiros.

c) Veljkovic, Koprivica, Radivojevic e Mileusnic (2018) pesquisaram sobre a aderência da análise de sensibilidade (com alterações em determinados fatores) na mensuração da margem de contribuição por vaca e por litro de leite de propriedades rurais sérvias.

d) Zin, Bombana e Barcellos (2018) objetivaram adaptar a matriz BCG na avaliação de equipe de vendas de duas companhias semelhantes, relacionando as vendas com as margens de contribuição respectivas.

e) Santos et al. (2018) evidenciaram possibilidades de ações para melhorias na Margem de Contribuição (MC) das vendas de distribuidora de mercadorias.

f) Hastenteufel e Larentis (2015) abordaram os procedimentos necessários para avaliar a lucratividade dos clientes de fábrica de móveis utilizando a margem de contribuição.

\subsection{Pesquisas anteriores sobre o impacto do ciclo financeiro no resultado da venda}

No que concerne a estudos acerca da relação entre os prazos do ciclo financeiro e a mensuração do resultado de produtos foram encontradas poucas publicações a respeito, conforme destacado na sequência. 
Wernke (2020) discorreu sobre a identificação do efeito dos prazos do ciclo financeiro na lucratividade das vendas de uma empresa atacadista e apresentou os resultados "com" e "sem" a consideração desses prazos. Além de evidenciar os resultados no contexto encontrado, simulou as alterações decorrentes do alongamento no prazo de recebimento de clientes.

O foco da pesquisa de Wernke e Junges (2020) foi medir o impacto da duração do ciclo financeiro na lucratividade das vendas de lojas franqueadas de surfwear para apontar o resultado segmentado por fornecedores.

No caso do artigo de Wernke, Francisco e Junges (2016) o objetivo consistiu na demonstração de como os prazos atrelados ao ciclo financeiro podem interferir na lucratividade das vendas de uma cooperativa de rizicultores, especialmente pela ocorrência de longos períodos de estocagem dos produtos agrícolas.

Por último, a pesquisa de Wernke, Junges, Correa e Zanin (2016) versou sobre a mensuração dos efeitos dos prazos de estoque, vendas e compras no âmbito de uma revendedora de carros usados.

Ao analisar as publicações comentadas é pertinente salientar que todas utilizaram a equação sugerida por Assaf Neto (2014), que permite apurar o resultado da venda computando os efeitos do ciclo financeiro, mas não considera o montante necessário de capital de giro para suportar a comercialização.

De forma semelhante, naquelas publicações que propuseram aprimoramentos na margem de contribuição também não foram encontrados estudos que conciliassem na apuração do resultado dos produtos a margem de contribuição, o ciclo financeiro e o valor do capital de giro que a empresa deve dispor para pagar fornecedores e tributos antes de receber a venda de seus clientes. Desse modo, emerge uma lacuna de pesquisa que pode ser mais explorada, como pretendido nesta pesquisa.

\section{Aspectos metodológicos}

No que tange às características metodológicas esta pesquisa pode ser qualificada por três ângulos:

1) Tipologia do objetivo: é um estudo exploratório porque esta categoria caracteriza as pesquisas que visam se aprofundar nos assuntos abordados, de forma a torná-los mais claros e possibilitar melhor delineamento e resposta ao problema apresentado (Beuren, 2012). Para essa finalidade, de acordo com Gil (2014), pode abranger levantamentos bibliográficos e documentais, entrevistas não padronizadas e estudos de caso.

2) Abordagem do problema pesquisado: é uma pesquisa de cunho qualitativo porque se assemelha aos estudos que visam evidenciar a complexidade de determinado problema por meio da 
análise da interação de variáveis específicas, com a intenção de compreender e classificar os processos dinâmicos vividos por determinados grupos sociais (Richardson, 2017).

3) Procedimento metodológico: classifica-se como um estudo de caso porque Yin (2014) menciona que esta modalidade representa uma investigação empírica que estuda um fenômeno contemporâneo em seu contexto real, especialmente quando os limites entre o fenômeno e o contexto não estão claramente determinados. Nesse rumo, foram seguidos os critérios propostos por Marques, Camacho e Alcantara (2015) para assegurar o rigor metodológico para este tipo de pesquisa quanto ao objeto de estudo, à coleta/análise dos dados e aos resultados decorrentes.

Quanto ao contexto empresarial abrangido, este estudo ocorreu entre outubro e novembro de 2020 e foi fundamentado nos dados de outubro do mesmo ano. O objeto estudado foi uma fábrica de artefatos de cimento sediada em município do sul de Santa Catarina e que contava com seis funcionários. Convém salientar que a identificação da empresa foi omitida porque não foi autorizada pelos proprietários do negócio e que a escolha desta fábrica como objeto de pesquisa ocorreu pela facilidade de acesso aos dados (disponibilizados pelos gestores), bem como pelas características do mix de produtos ofertados (número reduzido de itens, consumo de poucos tipos de matérias-primas etc.), o que facilitou o trabalho do pesquisador.

No que concerne ao levantamento dos dados necessários, primeiramente foram utilizadas entrevistas não estruturadas para conhecer a situação vigente acerca dos controles internos adotados e políticas comerciais utilizadas. Segundo Rauen (2015), esta é uma forma de entrevista geralmente utilizada em pesquisas qualitativas na qual as perguntas não são previamente redigidas e a interação acontece como uma conversa informal com o fito de obter determinadas informações.

Na sequência, para coletar os dados necessários para execução da pesquisa foram utilizados os controles internos mantidos pela gerência da empresa (ficha técnica dos produtos, software de faturamento, controle de estoques etc.), além de outras informações mais específicas repassadas pelos responsáveis pelos setores, quando cabível. Assim, os dados coletados podem ser segregados nas seguintes categorias:

a) Dados monetários (R\$) e quantidades vendidas dos produtos: mesmo que tenham sido comercializados 18 tipos de artefatos de cimento no mês-base do estudo, por ter apenas finalidade de pesquisa (e não de "consultoria empresarial") foram levantados dados acerca dos dois produtos mais vendidos no período para testar a metodologia de avaliação proposta. Nesse sentido, foram coligidos dados relacionados ao faturamento de outubro de 2020, que abrangem o valor total vendido dos dois principais produtos e da respectiva tributação 
incidente, bem como o custo de aquisição dos insumos consumidos na fabricação, o custo de transformação e o custo total de matérias-primas de cada produto considerando a quantidade faturada no período.

b) Taxa de juros: como os dados utilizados no estudo envolvem valores monetários (relativos a faturamento, custos e tributos) e os respectivos prazos que integram o ciclo financeiro desta pequena fábrica, para considerar o "valor do dinheiro no tempo" foi utilizada uma taxa de juros mensal para representar o custo de oportunidade do capital alocado nas operações comerciais de compra de insumos e venda de produtos.

c) Duração do ciclo financeiro: envolve os prazos médios (em dias) de recebimento das vendas, de estocagem das matérias-primas, de pagamento das compras dos insumos consumidos na fabricação dos artefatos de cimento e de quitação dos tributos incidentes sobre o faturamento.

\section{Apresentação dos dados e análise dos resultados da pesquisa}

A proposta de avaliação do resultado financeiro da venda dos produtos está alicerçada na equação a seguir: RFV = (VT-CMP-CTR-TRIB $)-[[(\mathrm{VT} / 30 \mathrm{~d}) *(\mathrm{PME}+\mathrm{PMR}-\mathrm{PMP})] * \mathrm{TJ} \%]$. Como o modelo matemático proposto abrange a margem de contribuição e as despesas financeiras decorrentes da necessidade de capital de giro e da extensão do ciclo financeiro, as próximas seções destacam os passos necessários para obter tais informações no contexto de uma empresa fabril, além de evidenciar os resultados oriundos da metodologia aplicada.

\subsection{Levantamento dos dados e cálculo do ciclo financeiro}

Para atingir o objetivo mencionado é necessário obter os prazos que integram o ciclo financeiro de cada produto visado. Nesse sentido, no caso dos dois produtos de maior faturamento da pequena indústria abrangida foram inicialmente levantados os dados cabíveis para determinar o prazo médio de pagamento dos fornecedores das matérias-primas consumidas. Então, a partir da ficha técnica de cada produto foi evidenciado o total das unidades de matérias-primas consumidas na fabricação e respectivos valores totais (R\$), como exemplificado na linha " $e$ " da Tabela 1 para o produto "Paver

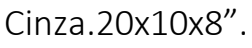


Tabela 1 - Prazo médio de pagamento de fornecedores e ficha técnica do produto Paver Cinza.20x10x8

\begin{tabular}{lrrrrrr}
\hline & 20 & 21 & 22 & 23 & 24 & Total \\
Itens & Cimento & Aditivo & Pedrisco & Areia Gr. & Areia Fina & - \\
\hline a) Quantidade consumida (unid.) & 21,0833 & 0,0639 & 19,1667 & 0,0465 & 0,0286 & - \\
b) Custo de compra unitário R\$ & 0,5400 & 0,1592 & 0,0033 & 50,00 & 33,00 & - \\
c=a*b) Custo unit. mat.-prima R\$ & 11,3850 & 0,0102 & 0,0629 & 2,3252 & 0,9444 & - \\
d) Quantidade vendida (unid.) & 1.002 & 1.002 & 1.002 & 1.002 & 1.002 & $14.757,13$ \\
e=c*d) Custo total mat.-prima R\$ & $11.407,77$ & 10,19 & 63,06 & $2.329,83$ & 946,27 & - \\
f) Prazo de pagamento (dias) & 5 & 21 & 28 & 15 & 15 & $108.160,16$ \\
g=e*f) Valor ponderado R\$ & $57.038,85$ & 214,02 & $1.765,71$ & $34.947,51$ & $14.194,06$ & 7,33 \\
h=g/h) Prazo médio linear de pagamento (em dias) dos fornecedores de matérias-primas & & &
\end{tabular}

Em seguida foi multiplicado o custo total de cada insumo pelo respectivo prazo de pagamento concedido pelos fornecedores (linha "f") para obter o valor ponderado destes, conforme consta da linha "g" da Tabela 1. Assim, para apurar o prazo médio linear de pagamento (dias) das compras foi necessário dividir o valor ponderado total $(\mathrm{R} \$ 108.160,16)$ pelo custo total das matérias-primas consumidas (R\$ 14.757,13), o que resultou em 7,33 dias de prazo médio de fornecedores para o "Paver Cinza.20x10x8".

Porém, o prazo de pagamento de fornecedores é um dos componentes dos prazos de pagamentos relacionados ao produto vendido, que deve abranger também os valores dos tributos incidentes na venda (no caso da empresa em tela apenas o Simples) e o custo de fabricação, como exemplificado na Tabela 2.

Tabela 2 - Prazo médio linear dos pagamentos do produto Paver Cinza.20x10x8

\begin{tabular}{lrrr}
\hline Itens & Valor Mensal R\$ & Prazo Pagamento (dias) & Valor Ponderado R\$ \\
\hline Fornecedores de matérias-primas (total) & $14.757,13$ & 7,33 & $108.160,16$ \\
Tributos da venda (total) & $3.029,89$ & 25 & $75.747,21$ \\
Custo de fabricação (total) & $6.584,89$ & 20 & $131.697,84$ \\
Total & $24.371,91$ & - & $315.605,21$ \\
Prazo médio linear de pagamentos (em dias) da empresa & & 12,95 \\
\hline
\end{tabular}

Fonte: Elaborada pelo autor.

Portanto, considerando os três fatores citados, a partir dos valores e prazos de pagamentos respectivos foi apurado que o prazo médio linear de pagamentos do produto de referência foi de 12,95 dias (R\$315.605,21/R\$24.371,91).

A etapa seguinte do levantamento de dados priorizou a determinação do prazo médio de estocagem das matérias-primas consumidas pelo produto, como ilustrado na Tabela 3. 
Tabela 3 - Prazo médio de estocagem dos insumos do produto Paver Cinza.20x10x8

\begin{tabular}{lrrr}
\hline Itens & $\begin{array}{r}\text { 1) Quantidade } \\
\text { Estocada (unid.) }\end{array}$ & $\begin{array}{r}\text { 2) Consumo } \\
\text { Total (unid.) }\end{array}$ & $\begin{array}{r}3=[1 / 2] * 30 \text { dias) Prazo } \\
\text { Médio de Estocagem (dias) }\end{array}$ \\
\hline Cimento & 32.300 & $21.125,50$ & 45,87 \\
Aditivo & 86 & 64,02 & 40,30 \\
Pedrisco & 21.537 & $19.205,00$ & 33,64 \\
Areia Gr. & 56 & 46,60 & 36,05 \\
Areia Fina & 42 & 28,67 & 43,94 \\
\hline
\end{tabular}

Fonte: Elaborada pelo autor.

Para apurar o prazo médio de estocagem foram considerados os volumes físicos estocados ao final do mês e o respectivo consumo das matérias-primas durante o período visado. Assim, como a quantidade estocada do "Cimento" foi de 32.300 quilos e o consumo mensal chegou a 21.125,50 quilos, o prazo médio de estocagem foi de 45,87 dias ( 32.300 quilos / 21.125,50 quilos * 30 dias).

Na sequência foi multiplicado o custo total do consumo de cada matéria-prima no mês (vide Tabela 1) pelos respectivos prazos médios de estocagem (em dias) para determinar o "valor ponderado", como consta da última coluna da Tabela 4.

Tabela 4 - Prazo médio linear de estocagem do produto Paver Cinza.20x10x8

\begin{tabular}{lrrr}
\hline Itens & Custo total mat.-prima R\$ & Prazo Médio Estoque (dias) & Valor Ponderado R\$ \\
\hline Cimento & $11.407,77$ & 45,87 & $523.260,00$ \\
Aditivo & 10,19 & 40,30 & 410,74 \\
Pedrisco & 63,06 & 33,64 & $2.121,56$ \\
Areia Gr. & $2.329,83$ & 36,05 & $84.000,00$ \\
Areia Fina & 946,27 & 43,94 & $41.580,00$ \\
Total & $14.757,13$ & - & $651.372,29$ \\
Prazo médio linear de pagamento (em dias) do produto & & 44,14 \\
\hline
\end{tabular}

Fonte: Elaborada pelo autor.

No caso do produto "Paver Cinza.20×10×8", como o valor total consumido de matérias-primas foi de $\mathrm{R} \$ 14.757,13$ e o valor total ponderado pelos prazos de armazenagem de cada insumo foi de $\mathrm{R} \$$ 651.372,29, chegou-se ao prazo médio de estocagem de 44,14 dias.

A etapa seguinte de levantamento de dados envolveu o conhecimento do prazo médio de recebimento das vendas. Acerca disso, o gestor informou que a empresa vendia nas condições de "à vista" e/ou com prazos que poderiam ir de 30 dias a 90 dias. Assim, como os valores respectivos eram bem diferentes, foi necessário calcular o prazo médio linear a partir do faturamento do mês utilizado como base nesta pesquisa, como exemplificado na Tabela 5. 
Tabela 5 - Prazo médio linear de vendas da empresa

\begin{tabular}{lrrr}
\hline Item & Vendas R\$ & Prazo de Recebimento (dias) & Valor Ponderado R\$ \\
\hline Vendas à Vista & $6.022,67$ & - & - \\
Vendas com 30 dd & $36.336,06$ & 30 & $1.090 .081,80$ \\
Vendas com 45 dd & $22.579,47$ & 45 & $1.016 .076,25$ \\
Vendas com 60 dd & $28.100,78$ & 60 & $1.686 .046,53$ \\
Vendas com 90 dd & $18.080,47$ & 90 & $1.627 .242,12$ \\
Total & $111.119,45$ & - & $5.419 .446,70$ \\
Prazo médio linear de recebimento (em dias) da empresa & & 48,77 \\
\hline
\end{tabular}

Fonte: Elaborada pelo autor.

No cálculo citado foram considerados os valores totais faturados no período, sem detalhar por produto comercializado porque os controles internos da empresa não permitiam essa forma de segregação. Assim, para todos os produtos foi considerado o prazo médio de recebimento da empresa de 48,77 dias.

Tendo em vista a disponibilidade dos prazos de recebimento, estocagem e pagamento conforme comentado nos parágrafos anteriores, foi determinado o ciclo financeiro da empresa pesquisada considerando a realidade de cada um dos produtos priorizados. Para essa finalidade foi utilizada a equação mais mencionada na literatura (Wernke, 2020; Kabuye et al., 2018; Oseifuah, 2018; Assaf Neto, 2014), que envolve a soma do prazo de recebimento (PR) com o prazo de estocagem (PE) e a posterior dedução do prazo de pagamentos (PP).

Concluiu-se, então, que o produto "Paver Cinza.20×10z8" apresentava ciclo financeiro de 85,58 $(48,77+44,14-7,33)$ dias e o "Piso I.Concr.Nat.22×11x8" tinha ciclo de conversão de caixa de 68,33 $(42,53+35,28-9,48)$ dias. Com isso, se pode considerar que, no caso do primeiro produto, a empresa pagava suas dívidas com fornecedores e tributos aproximadamente 85,58 dias antes de receber as vendas que faturou para seus clientes. Então, para suportar esse período entre o desembolso e o ingresso de recursos, a gerência da fábrica tem que disponibilizar capital para financiar o ciclo financeiro, conforme destacado na próxima seção.

\subsection{Necessidade de capital de giro e despesas financeiras decorrentes}

A metodologia mais conhecida para apurar o valor da necessidade de capital de giro requer a disponibilidade de demonstrativos contábeis que permitam identificar os valores monetários relacionados como o Ativo Circulante Operacional e o Passivo Circulante Operacional (Fleuriet, Kehdy, \& Blanc, 2003; Machado, Machado, \& Callado, 2006). Entretanto, tal procedimento de cálculo não permite considerar as características específicas de cada produto, pois evidencia a realidade da empresa e não dos segmentos de comercialização (produtos, grupos, clientes etc.).

Então, para estimar a necessidade de capital de giro de determinado produto (por exemplo) pode ser utilizada a equação que leva em conta (i) a duração (em dias) do ciclo financeiro de cada 
segmento de mercado visado, cujo valor deve ser multiplicado pelo (ii) valor da venda média diária respectiva (Santana, Backes, \& Demarchi, 2009), como demonstrado na Tabela 6.

Tabela 6 - Necessidade de capital de giro e despesas financeiras

\begin{tabular}{lrr}
\hline Produtos & Paver Cinza.20x10x8 & Piso I.Concr.Nat.22x11x8 \\
\hline a) Venda total do mês R\$ & $35.772,00$ & $35.760,00$ \\
b) Dias de venda por mês & 30 & 30 \\
$\mathrm{c}=\mathrm{a} / \mathrm{b}$ ) Venda média diária R\$ & $1.192,40$ & $1.192,00$ \\
d) Ciclo financeiro (dias) & 85,58 & 68,33 \\
$\mathrm{e}=\mathrm{c}^{*}$ d) Necessidade de capital de giro (NCG) R\$ & $102.047,40$ & $81.449,36$ \\
f) Taxa de captação de recursos (\% ao mês) & $1,51 \%$ & $1,51 \%$ \\
$\mathrm{~g}=\mathrm{e}^{*} \mathrm{f}$ ) Despesa financeira da NCG R\$ & $1.540,92$ & $1.229,89$ \\
\hline
\end{tabular}

Fonte: Elaborada pelo autor.

O cálculo demonstrado na Tabela 6 assume que as vendas diárias do "Paver Cinza.20x10x8" foram de $\mathrm{R} \$ 1.192,40$, que foi obtido pela divisão do valor faturado no mês $(R \$ 35.772,00)$ por 30 dias. Ao multiplicar esse valor monetário pela duração do ciclo financeiro de 85,58 dias chega-se ao montante de $\mathrm{R} \$ 102.047,40$, que pode ser interpretado como o valor do capital de giro que a empresa precisa dispor para suportar o recebimento da venda quase 86 dias depois do pagamento de fornecedores, tributos e custos fabris. Ou seja, necessita de montante equivalente a $285,27 \%$ do faturamento mensal deste produto para financiar a venda para seus clientes no contexto existente à época da pesquisa.

Como o produto mencionado requer a disponibilidade de $\mathrm{R} \$ 102.047,40$ a título de capital de giro e admitindo-se que a empresa precise captar tal valor à taxa de 1,51\% ao mês, teria despesa financeira de $\mathrm{R} \$ 1.540,92$ somente por comercializá-lo com 85,58 dias de duração do ciclo financeiro.

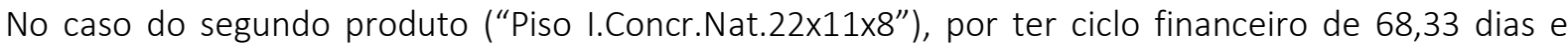
necessitar R\$ 81.449,36 de capital de giro, a despesa financeira decorrente pode ser estimada em $\mathrm{R} \$$ $1.229,89$.

O conhecimento da margem de contribuição e do ciclo financeiro de cada mercadoria possibilita associar esses dois conceitos financeiros para avaliar melhor o resultado, como descrito na sequência.

\subsection{Fórmula proposta para apurar o resultado financeiro da venda}

Os dados levantados até este ponto facultam avaliar o resultado dos produtos pela margem de contribuição e pela metodologia evidenciada neste estudo, que considera também o efeito dos prazos do ciclo financeiro no resultado de cada mercadoria, bem como a necessidade de capital de giro respectiva. Nesse sentido, propõe-se a equação exemplificada no Quadro 1, com dados numéricos relativos ao produto "Paver Cinza.20×10×8". 


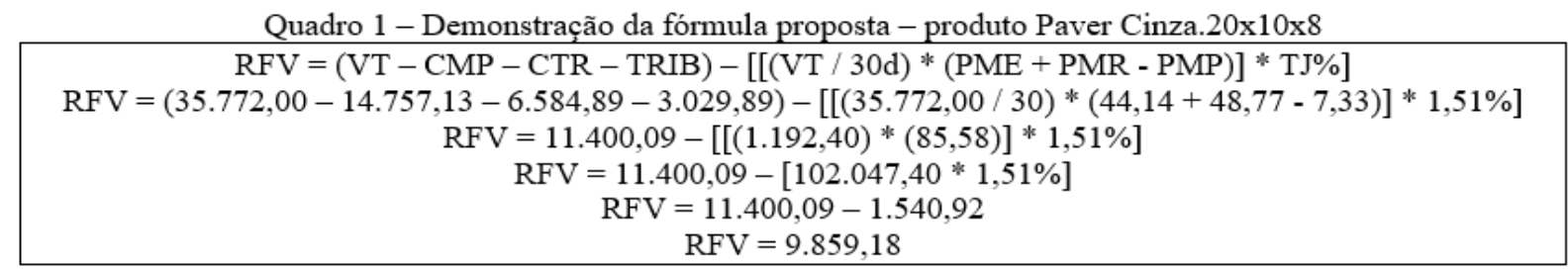

Quadro 1 - Demonstração da fórmula proposta - produto Paver Cinza.20x10x8

Fonte: Elaborado pelo autor.

No exemplo apresentado, a primeira parte da equação envolve os fatores tradicionalmente envolvidos na apuração da margem de contribuição fabril (Anthony \& Govindarajan, 2002), que abrange as vendas totais (VT) de $\mathrm{R} \$ 35.772,00$, o consumo de matérias-primas (CMP) no valor de $\mathrm{R} \$ 14.757,13$, o custo de transformação (CTR) de R\$ 6.584,89 e os tributos incidentes sobre o faturamento (TRIB) de $\mathrm{R} \$ 3.029,89$. Ou seja, a margem de contribuição total deste produto no mês foi de $\mathrm{R} \$ 11.400,09$.

Para computar os efeitos do ciclo financeiro e da necessidade de capital de giro decorrente, nesta pesquisa se propõe também a dedução das despesas financeiras oriundas da captação de recursos para essa finalidade, o que pode ser conseguido com a inserção da segunda parte da fórmula mencionada no Quadro 1, onde:

1) Venda média por dia (VT/30d): este valor é calculado dividindo o valor da venda mensal total (VT) por 30 dias, o que resultou em $\mathrm{R} \$ 1.192,40$.

2) Ciclo financeiro em dias (PME+PMR-PMP): ao somar o prazo médio de estocagem (PME) de 44,14 dias com o prazo médio de recebimento (PMR) de 48,77 dias e descontar o prazo médio de pagamentos (PMP) de 7,33 dias, foi apurado que o ciclo de conversão de caixa foi de 85,58 dias no caso em tela.

3) Taxa de juros (TJ\%): este fator refere-se à taxa do custo de oportunidade (Martins, 2018), que pode representar o "custo financeiro" da captação de recursos para aplicar no capital de giro necessário para suportar a duração do período entre o prazo médio de pagamento e o prazo médio de recebimento. No contexto da pequena empresa mencionada foi adotada a taxa de juros de $1,51 \%$ ao mês, tendo em vista ser este o custo de captação à época do estudo, conforme informado pelo gestor.

Com esses três fatores foi possível calcular a necessidade de capital de giro relativa ao produto ( $R \$ 102.047,40)$ com a multiplicação do valor da venda média diária $(R \$ 1.192,40)$ pela extensão do ciclo financeiro (85,58 dias). Então, assumindo-se que tal montante seja captado à taxa de juros de 1,51\% ao mês, tal operação acarreta despesa financeira no valor de $\mathrm{R} \$ 1.540,92$. Portanto, ao deduzir este valor 
da margem de contribuição fabril do produto ( $R \$ 11.400,09)$, obtém-se o resultado financeiro da venda (RFV) de R\$9.859,18.

A próxima seção analisa os resultados da aplicação da fórmula sugerida e faz o cotejamento com outras pesquisas.

\subsection{Análise dos resultados e cotejamento com estudos anteriores}

Uma forma de analisar o efeito no resultado da forma de avaliação proposta consiste em confrontar os resultados "com" e "sem" a aplicação desta metodologia, bem como comparar o desempenho dos itens comercializados. Nesse sentido, a Tabela 7 evidencia o resultado financeiro detalhado dos dois principais produtos da pequena empresa pesquisada.

Tabela 7 - Resultado financeiro por produto

\begin{tabular}{|c|c|c|c|c|c|}
\hline \multirow[b]{2}{*}{ Itens } & \multicolumn{2}{|c|}{ Paver Cinza. $20 \times 10 \times 8$} & \multicolumn{2}{|c|}{ Piso I.Concr.Nat. $22 \times 11 \times 8$} & \multirow{2}{*}{$\begin{array}{r}\text { Diferença } \\
\text { Valores RS }\end{array}$} \\
\hline & Valores R\$ & $\%$ das Vendas & Valores R\$ & $\%$ das Vendas & \\
\hline$(+)$ Vendas R\$ & $35.772,00$ & $100,00 \%$ & $35.760,00$ & $100,00 \%$ & 12,00 \\
\hline (--) Tributos da venda RS & $3.029,89$ & $8,47 \%$ & $3.028,87$ & $8,47 \%$ & 1,02 \\
\hline (--) Custo de matérias-primas R\$ & $14.757,13$ & $41,25 \%$ & $14.995,20$ & $41,93 \%$ & $-238,07$ \\
\hline (--) Custo de transformação RS & $6.584,89$ & $18,41 \%$ & $6.585,60$ & $18,42 \%$ & $-0,71$ \\
\hline (=) Margem de contribuição fabril RS & $11.400,09$ & $31,87 \%$ & $11.150,33$ & $31,18 \%$ & 249,76 \\
\hline (--) Despesa financeira da NCG R\$ & $1.540,92$ & $4,31 \%$ & $1.229,89$ & $3,44 \%$ & 311,03 \\
\hline$\Leftrightarrow$ Resultado financeiro da venda RS & $9.859,18$ & $27,56 \%$ & $9.920,44$ & $27,74 \%$ & $-61,26$ \\
\hline
\end{tabular}

Fonte: Elaborada pelo autor.

O demonstrativo do resultado por produto retratado na Tabela 7 permite analisar os resultados por três ângulos:

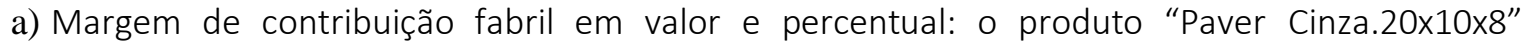
proporcionou $\mathrm{R} \$ 11.400,09$ de margem de contribuição, o que representou 31,87\% das vendas

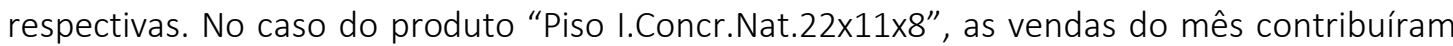
com $\mathrm{R} \$ 11.150,33$ para o resultado da empresa, equivalente a $31,18 \%$ do faturamento deste item. Ou seja, pelo critério tradicional de avaliação do resultado dos segmentos de mercado, o

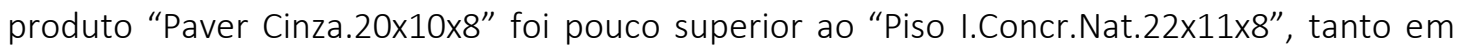
valor monetário gerado (R\$ 249,76 a mais), quanto em porcentagem da venda (0,69 ponto percentual maior).

b) Despesa financeira da NCG em valor e percentual: tendo em vista a necessidade de capital de giro e a duração do ciclo financeiro do produto "Paver Cinza.20×10×8", a estimativa de despesa financeira vinculada à NCG alcançou R\$1.540,92 (4,31\% do faturamento respectivo). Quanto ao "Piso I.Concr.Nat.22×11×8", a projeção de despesa financeira da NCG foi de R\$1.229,89 (o 


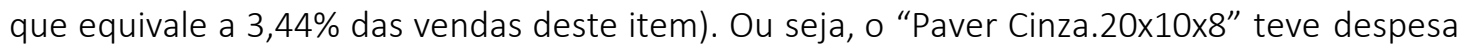

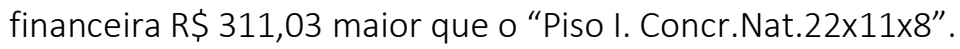

c) Resultado financeiro da venda em valor e percentual: o produto mais lucrativo por este critério

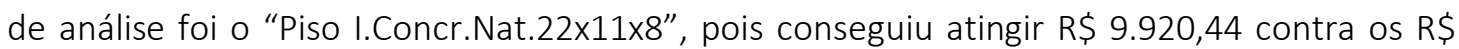

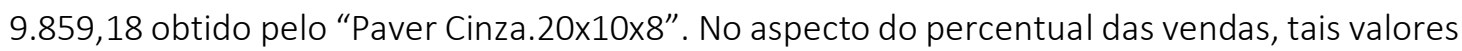
representaram 27,74\% e 27,56\%, respectivamente para "Piso I.Concr.Nat.22×11×8" e "Paver

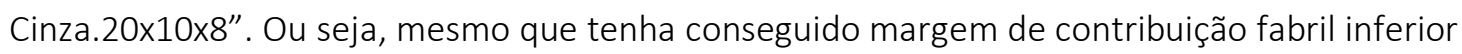

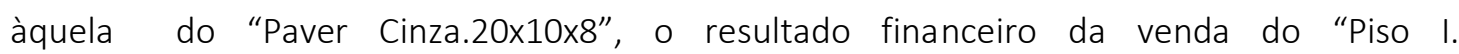

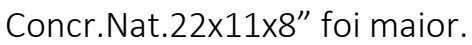

A partir do exposto é coerente cogitar que a causa da diferença no resultado ( $R \$ 61,26$ maior

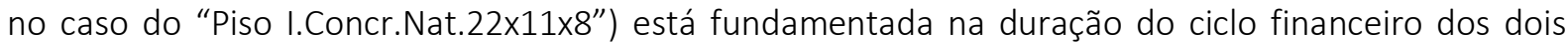
produtos, visto que tiveram vendas totais semelhantes (R\$ 12 de diferença a favor do "Paver

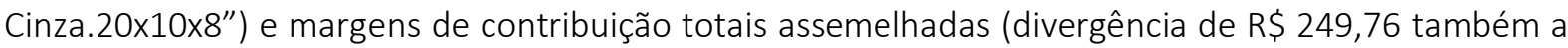
favor do "paver").

Entretanto, como o "paver" apresentou ciclo financeiro mais longo (85,58 dias contra 68,33 dias

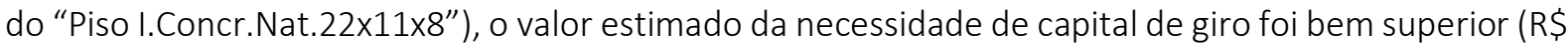

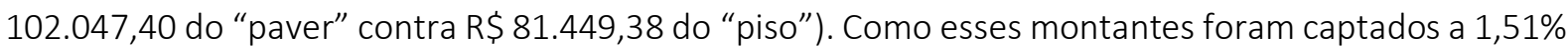
ao mês, a estimativa de despesa financeira para cada produto (R\$ 1.540,92 e $\operatorname{R} \$ 1.220,89$ respectivamente para "paver" e "piso") foi suficiente para inverter a ordem da contribuição para o lucro entre os dois. Ou seja, como a diferença em termos de margem de contribuição era de $\mathrm{R} \$ 249,76$ entre os produtos e a despesa financeira do "paver" foi $\mathrm{R} \$ 311,03$ superior ao outro item, o resultado financeiro da venda do "piso" passou a ser maior que o conseguido pelo "paver".

Do ponto de vista na participação percentual no faturamento mensal, a despesa financeira da NCG do "paver" representou 4,31\% das vendas, o que reduziu o resultado obtido de $31,87 \%$ para $27,56 \%$ da venda total do período. No que tange ao "piso", a despesa financeira equivaleu a $3,44 \%$ do valor vendido no mês, o que foi suficiente para reduzir o resultado de 31,18\% (margem de contribuição fabril) para $27,74 \%$ (resultado financeiro da venda).

O contexto descrito evidencia a coerência do raciocínio defendido neste estudo no sentido de que deve ser medido o impacto no resultado das despesas relacionadas com a captação de recursos para suprir a necessidade de capital de giro decorrente do ciclo financeiro de cada produto. Além de causar uma alteração de posicionamento no ranking de contribuição dos produtos, a evidenciação das despesas financeiras decorrentes do ciclo de conversão de caixa serve também para salientar a importância de avaliar a pertinência dos prazos de estocagem, recebimento e pagamento de cada item comercializado. 
Nesse sentido, a diferença de 17,25 dias entre os ciclos financeiros dos dois produtos $(85,58$ dias do "paver", contra 68,33 dias do "piso") foi ocasionada principalmente pelo tempo de estocagem (8,86 dias maior no caso do "paver") e pelo prazo de recebimento de clientes (com 6,24 dias a mais do "paver"). Também contribuiu (com menor grau de importância) o prazo médio de pagamentos, pois os fatores relacionados tiveram 2,15 dias a mais de prazo para quitação no caso do "piso", em comparação com o prazo de pagamentos relativo ao "paver".

No que concerne ao cotejamento dos resultados desta pesquisa com estudos anteriores é pertinente destacar dois pontos.

Inicialmente é válido afirmar que a expansão dos fatores considerados no cálculo da margem de contribuição pode aprimorar a qualidade da informação gerencial relativa ao resultado dos produtos. Caso seja admitido o raciocínio de que é preciso dispor de capital de giro para suportar o ciclo financeiro e que decorrem despesas financeiras associadas a tal disponibilidade, provavelmente maior atenção será dada pelo gestor à avaliação da pertinência das políticas de estocagem, de concessão de prazos para clientes e de pagamento de fornecedores. Assim, em vez de avaliar o resultado somente pelos componentes do conceito tradicional de margem de contribuição (Martins, 2018), pela metodologia de aferição do resultado proposta tem-se um rol maior de fatores computados, o que se coaduna com as iniciativas anteriores de aprimoramento da margem de contribuição comentadas em seção precedente (Rojas, 2019; Santos et al., 2018).

O segundo aspecto a salientar é que o valor das despesas financeiras decorrentes do ciclo de conversão de caixa pode ser relevante a ponto de influenciar no resultado dos produtos e demais segmentos de mercado. Como visto no comparativo dos dois produtos priorizados neste estudo, as despesas financeiras relacionadas à duração do ciclo financeiro podem alterar a posição dos itens no ranking de contribuição para o lucro (ou mostrar um desempenho mais realista). Portanto, a mensuração do resultado na concepção ora sugerida se coaduna com as pesquisas mencionadas anteriormente que consideraram relevante apurar o efeito do ciclo de conversão de caixa no lucro das vendas (Wernke \& Junges, 2020; Wernke, 2019). Entretanto, este estudo pode ser considerado um aprimoramento em relação às pesquisas precedentes porque avalia o resultado da venda considerando os prazos do ciclo financeiro e as despesas financeiras decorrentes, além de disponibilizar informações sobre a necessidade de capital de giro relacionada ao mix de produtos.

\section{Considerações finais}

A análise do resultado de produtos costumeiramente é feita pela margem de contribuição, mas este conceito não considera alguns fatores relacionados à comercialização que podem influenciar o resultado dos produtos faturados (como as despesas financeiras oriundas da duração do ciclo financeiro 
e da respectiva necessidade de capital de giro). Então, o objetivo deste estudo consistiu em propor uma equação que permita medir o resultado do produto considerando a duração do ciclo financeiro e a decorrente necessidade de capital de giro no contexto de uma pequena indústria. Com base no exposto nas seções precedentes, tal objetivo foi atingido pela proposição de uma equação que considera esses aspectos no resultado financeiro dos produtos vendidos.

Ao aplicar a metodologia proposta foi possível concluir que o resultado de cada produto pode ser impactado se forem consideradas nessa avaliação as despesas financeiras decorrentes da duração do ciclo de conversão de caixa dos segmentos de mercado abrangidos. No âmbito dos dois itens utilizados nos exemplos, entre a margem de contribuição e o resultado medido conforme proposto nesta pesquisa foram apuradas despesas equivalentes a 4,31\% ("Paver") e 3,44\% ("Piso") do preço de venda praticado, o que representa quedas de 13,52\% e 11,03\% respectivamente no valor monetário $(R \$)$ do resultado dos dois produtos entre as duas formas de avaliação. Essa divergência entre as duas possibilidades de aferição do resultado é um indicativo da relevância de dimensionar o ciclo financeiro dos produtos e a respectiva influência da extensão deste na geração de despesas financeiras por item faturado no período.

No que concerne às contribuições práticas e teóricas da pesquisa, podem ser evidenciados ao menos dois aspectos. A contribuição teórica consiste em propor uma equação que permite o cômputo das despesas financeiras decorrentes do volume de capital de giro necessário durante a extensão do ciclo financeiro de cada produto na análise da rentabilidade deste. Como tal aspecto não é considerado na margem de contribuição (que tradicionalmente tem sido utilizada para medir o resultado dos segmentos de mercado), seu cômputo torna-se relevante especialmente no caso da oferta de produtos que requerem a disponibilização de capital de giro para suportar a duração do ciclo financeiro respectivo, pois o montante dos recursos necessários pode reduzir o resultado e até inviabilizar a manutenção do item no mix ofertado.

Quanto à contribuição de cunho prático, esta reside na possibilidade de aplicação da fórmula proposta na realidade fabril até de pequenas indústrias (como retratado neste estudo). Isso ocorre porque os dados requeridos podem ser obtidos nos controles internos das empresas ou por meio de estimativas, conforme descrito nas seções anteriores. Com isso, também pode contribuir com a sociedade quando auxilia no aprimoramento da gestão deste porte de empresa, que é responsável por grande parte dos empregos gerados no Brasil.

Contudo, entre as limitações associáveis à metodologia apresentada é pertinente destacar o aspecto relacionado à definição da taxa de juros a ser utilizada como custo de oportunidade. No caso da empresa pesquisada, considerando a facilidade de obtenção e atualizações posteriores, optou-se por utilizar a taxa de captação de recursos para capital de giro vigente por ocasião do levantamento de dados, que foi informada pelo gestor principal da empresa. Entretanto, num contexto empresarial mais 
complexo provavelmente seria mais adequado utilizar o Custo Médio Ponderado de Capital (Faria, \& Costa, 2005) para coadunar-se melhor à realidade de uma organização mais complexa.

Quanto a recomendações para pesquisas futuras, sugere-se aplicar a equação proposta, de forma comparativa, em outros segmentos de mercado (como grupos ou linhas de produtos) de determinada empresa. Desse modo, haveria a possibilidade de confrontar os resultados dos segmentos visados para identificar os fatores relacionados ao ciclo financeiro que mais afetam o desempenho e cogitar iniciativas de melhoria.

\section{Referências}

Ahmed, S. U., Mahtab, N., Islam, N., \& Abdullah, M. (2017). Impact of working capital management on profitability: a study on textile companies of Bangladesh. Journal of Business \& Financial Affairs, 6(4), 1-7.

Altaf, N. (2018). Do financial development and law enforceability effect the relationship between net working capital and firm value? Empirical evidence from Asia. American Journal of Business, 33(3), 120-132, 2018.

Altaf, N., \& Shah, F. A. (2018a). How does working capital management affect the profitability of Indian companies? Journal of Advances in Management Research. Doi: https://doi.org/10.1108/JAMR-06-2017-0076

Altaf, N., \& Shah, F. A. (2018b). Investment and financial constraints in indian firms: Does working capital smoothen fixed investment. Decision: Official Journal of the Indian Institute of Management, 45(1), 43-58.

Aminu, Y., \& Zainudin, N. (2016). A review of anatomy of working capital management theories and the relevant linkages to working capital components: a theoretical building approach. European Journal of Business and Management, 7(2), 10-18.

Amponsah-Kwatiah, K., \& Asiamah, M. (2020). Working capital management and profitability of listed manufacturing firms in Ghana. International Journal of Productivity and Performance Management, Ahead-of-print, Doi: https://doi.org/10.1108/IJPPM-02-2020-0043

Anthony, R. N., \& Govindarajan, V. (2002). Sistemas de controle gerencial. São Paulo: Atlas.

Assaf Neto, A. (2014). Finanças corporativas e valor. 7ạ ed., São Paulo: Atlas.

Baker, H. K., Kumar, S., Colombage, \& Singh, H. P. (2017). Working capital management practices in India: survey evidence. Managerial Finance, 43(3), 331-353.

Beuren, I. M. (2012). Como elaborar trabalhos monográficos em contabilidade: teoria e prática. 3a ed. São Paulo, Atlas.

Bruni, A. L. (2013). Avaliação de investimentos. São Paulo: Atlas. 
Carvalho, C. J., \& Schiozer, R. F. (2012). Gestão de capital de giro: um estudo comparativo entre práticas de empresas brasileiras e britânicas. Revista de Administração Contemporânea, 16(4), 518-543.

Chang, C. C. (2018). Cash conversion cycle and corporate performance: global evidence. International Review of Economics \& Finance, 56, 568-581.

Dalci, I., \& Ozyapici, H. (2018). Working capital management policy in health care: the effect of leverage. Health Policy, 122(11), 1266-1272.

Faria, A. C. de, \& Costa, M. de F. G. da. (2005). Gestão de custos logísticos. São Paulo: Atlas.

Fleuriet, M., Kehdy, R. \& Blanc, G. (2003). O modelo Fleuriet: a dinâmica financeira das empresas brasileiras, 5a ed., Rio de Janeiro: Elsevier.

Gil, A. de L. (2014). Métodos e técnicas de pesquisa social. 6ạ ed., São Paulo: Atlas.

Gill, A. (2011). Factors that influence working capital requirements in Canada. Economics and Finance Review, 1(3), 30-40.

Gitman, L. J. (1997). Princípios de administração financeira. 9ạ ed., São Paulo: Harbra.

Gorondutse, A. H., Ali, R. A., Abubakar, A., \& Naalah, M. N. I. (2017). The effect of working capital management on SMEs profitability in Malaysia. Polish Journal of Management Studies, 16(2), 99-109.

Guerreiro, R. (2011). Estruturação de sistemas de custos para a gestão da rentabilidade. São Paulo: Atlas.

Hastenteufel, C., \& Larentis, F. (2015). Analysing customers profitability via contribution margin: a study in a business sector of medium size furniture located in Serra Gaúcha. Revista Produção e Desenvolvimento, 1(1), 60-76.

Jana, D. (2018). Impact of working capital management on profitability of the selected listed FMCG companies in India. International Research Journal of Business Studies, 11(1), 21-30.

Kabuye, F., Kato, J., Akugizibwe, I., \& Bugambiro, N. (2018). Internal control systems, working capital management and financial performance of supermarkets. Cogent Business \& Management, 6(1), 1-18.

Kalaivani, P., \& Jothi, K. (2017). Impact of working capital management on profitability of the select car manufacturing companies in India. International Journal of Pure and Applied Mathematics, 116(24), 13-21.

Kasozi, J. (2017). The effect of working capital management on profitability: a case of listed manufacturing firms in South Africa. Investment Management and Financial Innovations, 14(2), 336-346.

Machado, M. A. V., Machado, M. R., \& Callado, A. L. C. (2006). Análise dinâmica e o financiamento das necessidades de capital de giro das pequenas e médias empresas localizadas em cidade de João Pessoa, PB: um estudo exploratório. Base - Revista de Administração e Contabilidade da Unisinos, 3(2), 139-149. 
Marques, K. C. M., Camacho, R. R., \& Alcantara, C. C. V. de. (2015). Avaliação do rigor metodológico de estudos de caso em contabilidade gerencial publicados em periódicos no Brasil. Revista Contabilidade \& Finanças - USP, 26(67), 27-42.

Martins, E. (2018). Contabilidade de Custos. 11a ed. São Paulo: Atlas.

Martins, E., \& Rocha, W. (2010). Métodos de custeio comparados: custos e margens analisadas sob diferentes perspectivas. São Paulo: Atlas.

Mielcarz, P., Osiichuk, D., \& Wnuczak, P. (2018). Working capital management through the business cycle: evidence from the corporate sector in Poland. Contemporary Economics, 12(2), 223237.

Mohamad, N. E. Z. B., Rahman, N. R. B. A., \& Saad, N. B. M. (2017). Linking working capital policy towards financial performance of small medium enterprise (SME) in Malaysia. SHS Web of Conferences 36(21). Doi: https://doi.org/10.1051/shsconf/20173600021

Nazir, M. S., \& Afza, T. (2009). Working capital requirements and the determining factors in Pakistan. IUP Journal of Applied Finance, 15(4), 28-38.

Nyeadi, J., Sare, Y. A., \& Aawaar, G. (2018). Determinants of working capital requirement in listed firms: empirical evidence using a dynamic system GMM. Cogent Economics \& Finance, 6(1). Doi: https://doi.org/10.1080/23322039.2018.1558713

Oseifuah, E. (2018). Global financial crisis, working capital management and profitability of nonfinancial firms listed on the Johannesburg Stock Exchange, South Africa. Academy of Entrepreneurship Journal, 24(3).

Pais, M. A., \& Gama, P. M. (2015). Working capital management and SMEs profitability: portuguese evidence. International Journal of Managerial Finance, 11(3), 341-358.

Palombini, N. V. N., \& Nakamura, W. T. (2012). Key factors in working capital management in the brazilian market. Revista de Administração de Empresas, 52(1), 55-69.

Prasad, P., Narayanasamy, S., Paul, S., Chattopadhyay, S., \& Saravanan, P. (2018). Review of literature on working capital management and future research. Journal of Economic Surveys. Doi: https://doi.org/10.1111/joes.1229

Quang, N. H. (2017). Impact of working capital management to business efficiency of association of Asia Pacific Airlines. International Journal of Mechanical Engineering and Applications, 5(4), 813.

Rauen, F. (2015). Roteiros de iniciação científica: os primeiros passos da pesquisa científica desde a concepção até a produção e a apresentação. Palhoça: Editora Unisul.

Respatia, W. (2017). Pengaruh analisis return on equity, economic value added, net working capital ratio Terhadap harga saham industry manufaktur di bursa efek Jakarta. Ekuitas - Jurnal Ekonomi dan Keuangan, 10(394).

Richardson, R. J. (2017). Pesquisa social: métodos e técnicas. 4ạ ed. São Paulo: Atlas. 
Rojas, F. (2019). Optimal contribution margin in food service using inventory control with statistical dependence. Revista Chilena de Ingeniería, 27(1), 89-100.

Santana, M. R., Backes, M. G, \& Demarchi, V. (2009). Gestão do capital de giro à luz da relação custo/volume/lucro. Revista Brasileira de Contabilidade, 175, 39-49.

Santos, J. A., Cruz, V. L., Santos, R. R. dos, \& Leone, R. J. G. (2018). Análise das estratégias de ganho de margem bruta em uma distribuidora de medicamentos. Exacta-EP, 16(2), 169-185.

Sawarni, K. S., Narayanasamy, S., \&Ayyalusamy, K. (2020). Working capital management, firm performance and nature of business: an empirical evidence from India. International Journal of Productivity and Performance Management, Ahead-of-print. Doi: https://doi.org/10.1108/IJPPM-10-2019-0468

Singh, H. P., \& Kumar, S. (2014). Working capital management: A literature review and research agenda. Qualitative Research in Financial Markets, 6(2), 173-197.

Silva, S. E. da, Camargos, M. A. de, Fonseca, S. E., \& Iquiapaza, R. A. (2019). Determinantes da necessidade de capital de giro e do ciclo financeiro das empresas brasileiras listas na B3. Revista Catarinense da Ciência Contábil, 18, 1-17, e2842.

Souza, B. C., \& Rocha, W. (2010). Modelo de análise de lucro na logística: conceitos importantes para as decisões. Revista Mundo Logística, 17, jul./ago.

Steffen, H. C., Zanini, F. A. M., Kronbauer, C. A., \& Ott, E. (2014). Administração do capital de giro: um estudo sobre os fatores que influenciam na criação de valor para a empresa. Revista Contabilidade Vista \& Revista, 25(1), 15-33.

Thakur, O. A., \& Mukit, D. M. A. (2017). Working capital financing policy and profitability: empirical study on Bangladeshi listed firms. British Journal of Economics, Management \& Trade, 17(1), $1-6$.

Tsuruta, D. (2018). Do working capital strategies matter? Evidence from small business data in Japan. Asia-Pacific Journal of Financial Studies, 47(6), 824-857.

Veljkovic, B., Koprivica, R., Radivojevic, D., \& Mileusnic, Z. (2018). Sensitivity of contribution margin in milk production on family farms. Journal of Central European Agriculture, 19(3), 658-678.

Viswanathan, V., Tillmanns, S., Krafft, M., \& Asselmann, D. (2018). Understanding the quality-quantity conundrum of customer referral programs: effects of contribution margin, extraversion, and opinion leadership. Journal of the Academy of Marketing Science, 46(6), 1108-1132.

Wernke, R. (2019). Análise de custos e preços de venda: ênfase em aplicações e casos nacionais. 2aa ed., São Paulo: Saraiva.

Wernke, R. (2020). Avaliação do efeito da concessão de prazo de recebimento maior no resultado das vendas: estudo intervencionista em rede de lojas atacadistas. Revista Capital Científico, 18(1), 45-63.

Wernke, R., \& Junges, I. (2020). Influência do ciclo financeiro na lucratividade: um estudo de caso em lojas franqueadas no segmento de surfwear. Revista da Micro e Pequena Empresa, 14(1), 4358. 
Wernke, R., \& Lembeck, M. (2004). Análise de rentabilidade dos segmentos de mercado de empresa distribuidora de mercadorias. Revista Contabilidade \& Finanças, 15(35), 68-83.

Wernke, R., Francisco, D. M., \& Junges, I. (2016). Efeito dos prazos no resultado das vendas de cooperativa de rizicultores: estudo de caso. Custos e @gronegócios Online, 12(4), 110-139.

Wernke, R., Junges, I., Correa, I. N., \& Zanin, A. (2016). Efeitos dos prazos de compra, estocagem e recebimento no resultado da venda: proposta para mensuração em revenda de automóveis usados. Revista Ambiente Contábil, 8(1), 133-152.

Yin, R. K. (2014). Estudo de caso: planejamento e método. 5a ed., Porto Alegre: Bookman.

Zin, R. A., Bombana, L. P., \& Barcellos P. F. (2018). Avaliação das equipes de vendas de duas empresas com a matriz BCG utilizando lucro e margem de contribuição. Gestão \& Produção, 25(4), 826838. 